\title{
Synthesis and Reactivity of Organometallic Complexes of Divalent Thulium with Cyclopentadienyl and Phospholyl Ligands.
}

\author{
Florian Jaroschik, François Nief*, Xavier Le Goff and Louis Ricard \\ Laboratoire Hétéroéléments et Coordination, CNRS, Ecole Polytechnique, Route de Saclay, \\ 91128 Palaiseau, France \\ francois.nief@polytechnique.edu
}

\section{Supporting information}

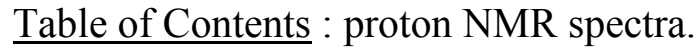

Compounds 3 and 4 S2

Compounds 5 and $\mathbf{6}$ S3

Compound 7 and $\left[\left(\mathrm{Cp}^{\mathrm{ttt}}\right)_{2} \mathrm{TmI}\right]$ S4

Compound 8, $\left[(\mathrm{Dtp})_{2} \mathrm{Tm}\right]$, and the 1:1 $\left[(\mathrm{Dtp})_{2} \mathrm{Tm}\right] /$ pyridine mixture S5 


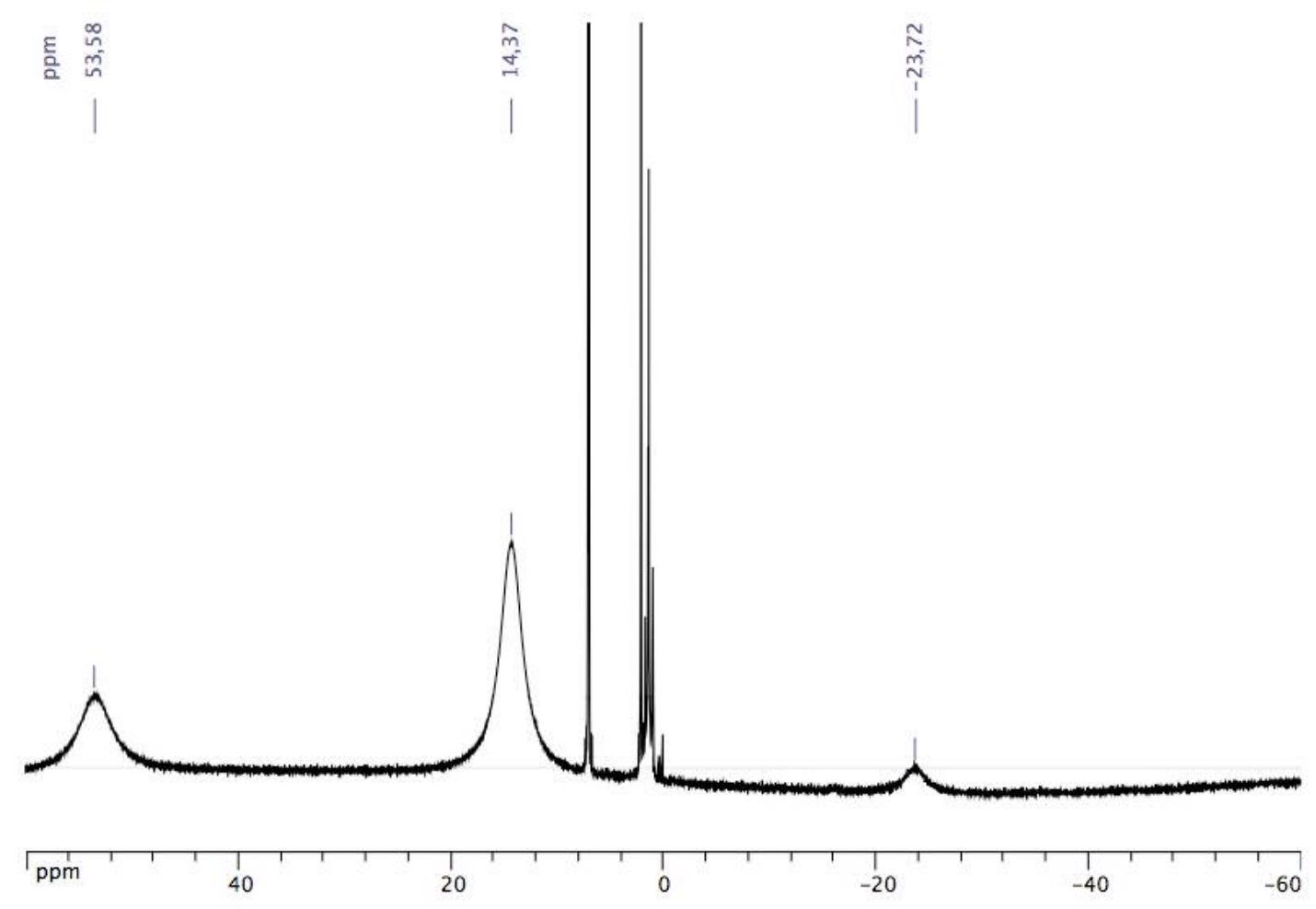

NMR spectrum of $\mathbf{3}$ in benzene-d $\mathrm{d}^{8}$.
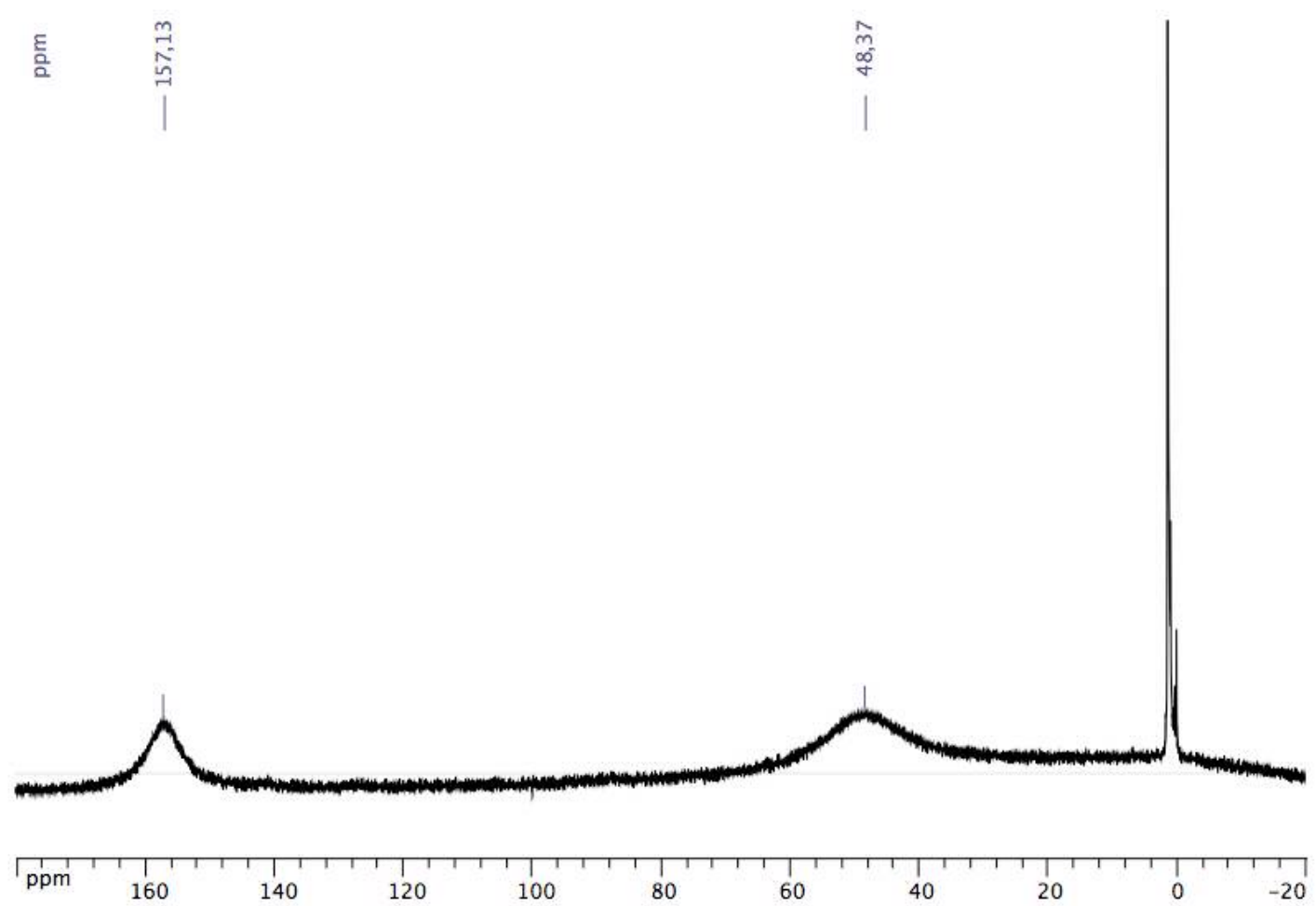

NMR spectrum of $\mathbf{4}$ in cyclohexane-d ${ }^{12}$. 


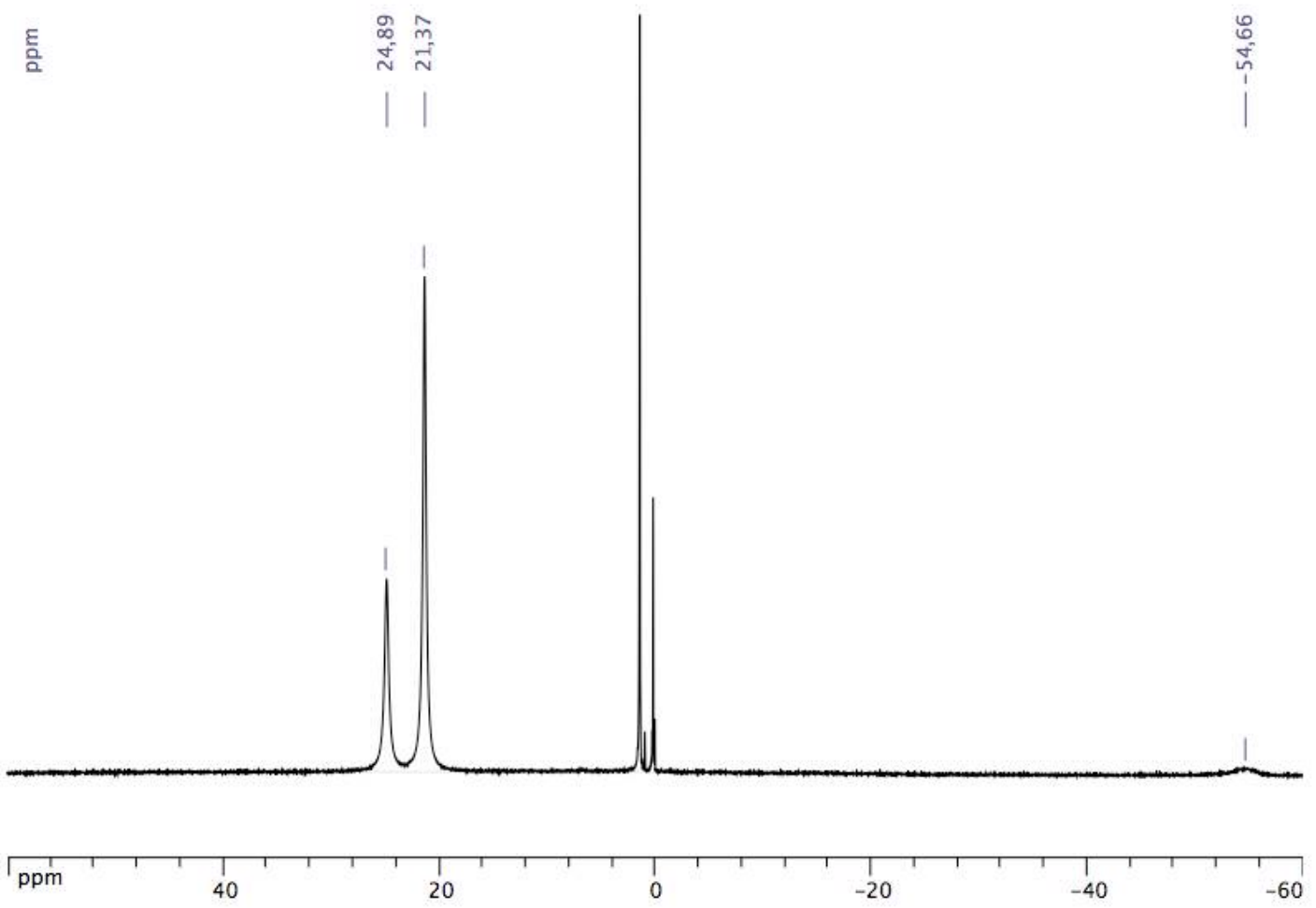

NMR spectrum of 5 in cyclohexane-d ${ }^{12}$.
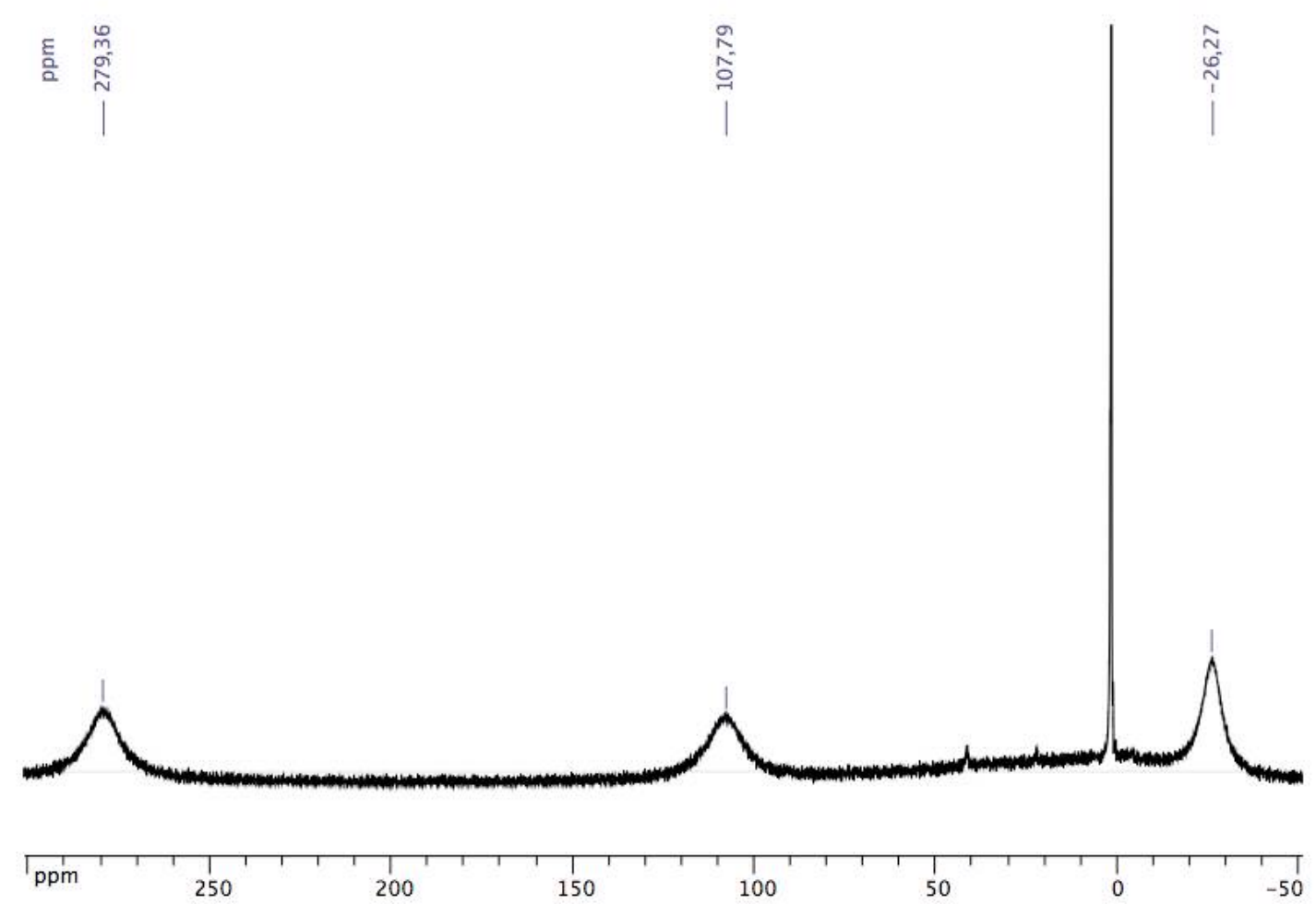

NMR spectrum of $\mathbf{6}$ in cyclohexane- $\mathrm{d}^{12}$ 


\section{E.}
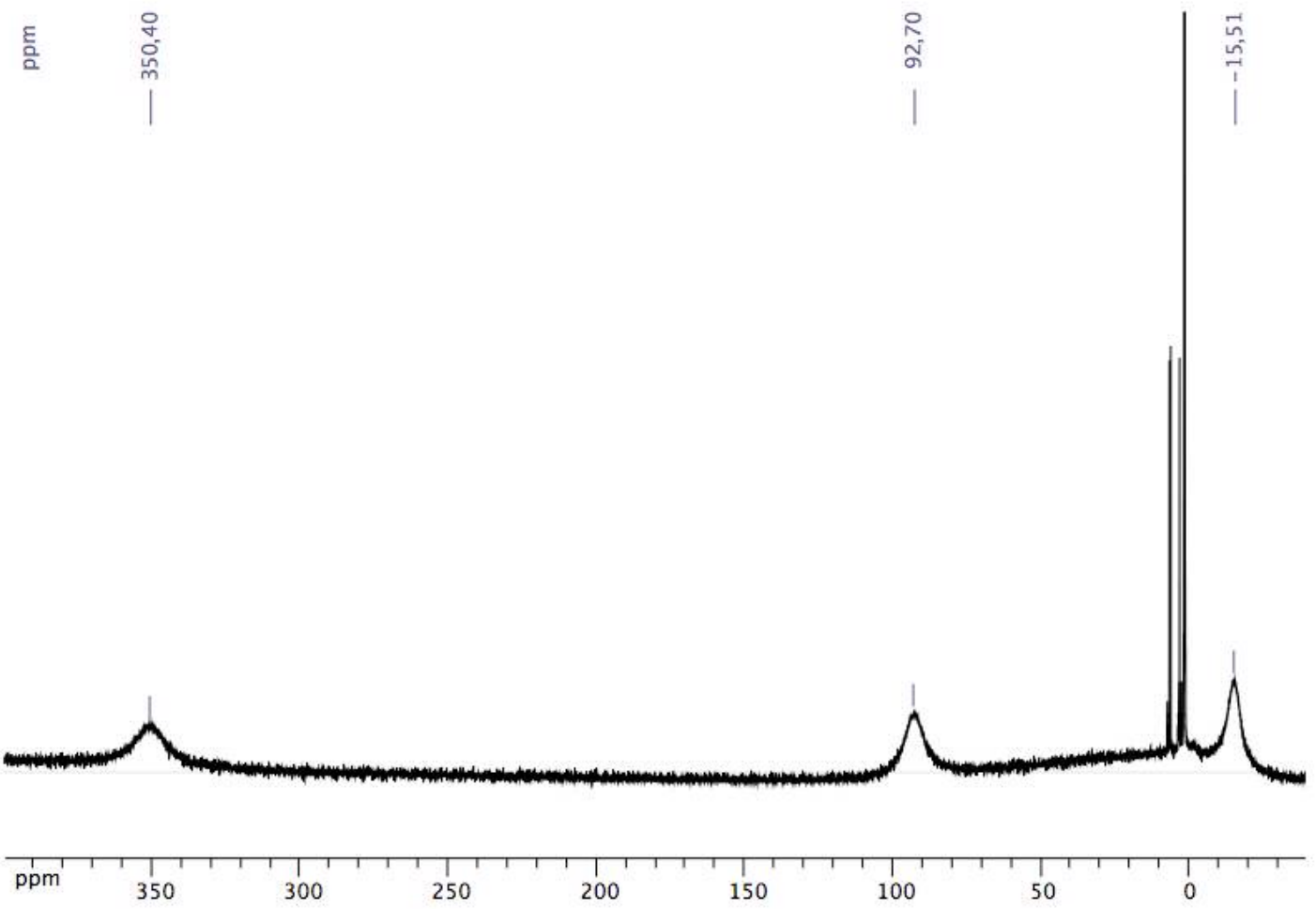

NMR spectrum of $\left[\left(\mathrm{Cp}^{\mathrm{ttt}}\right)_{2} \mathrm{TmI}\right]$ in cyclohexane-d $\mathrm{d}^{12}$.

E $\stackrel{\substack{n \\ 0}}{\stackrel{n}{\sim}}$
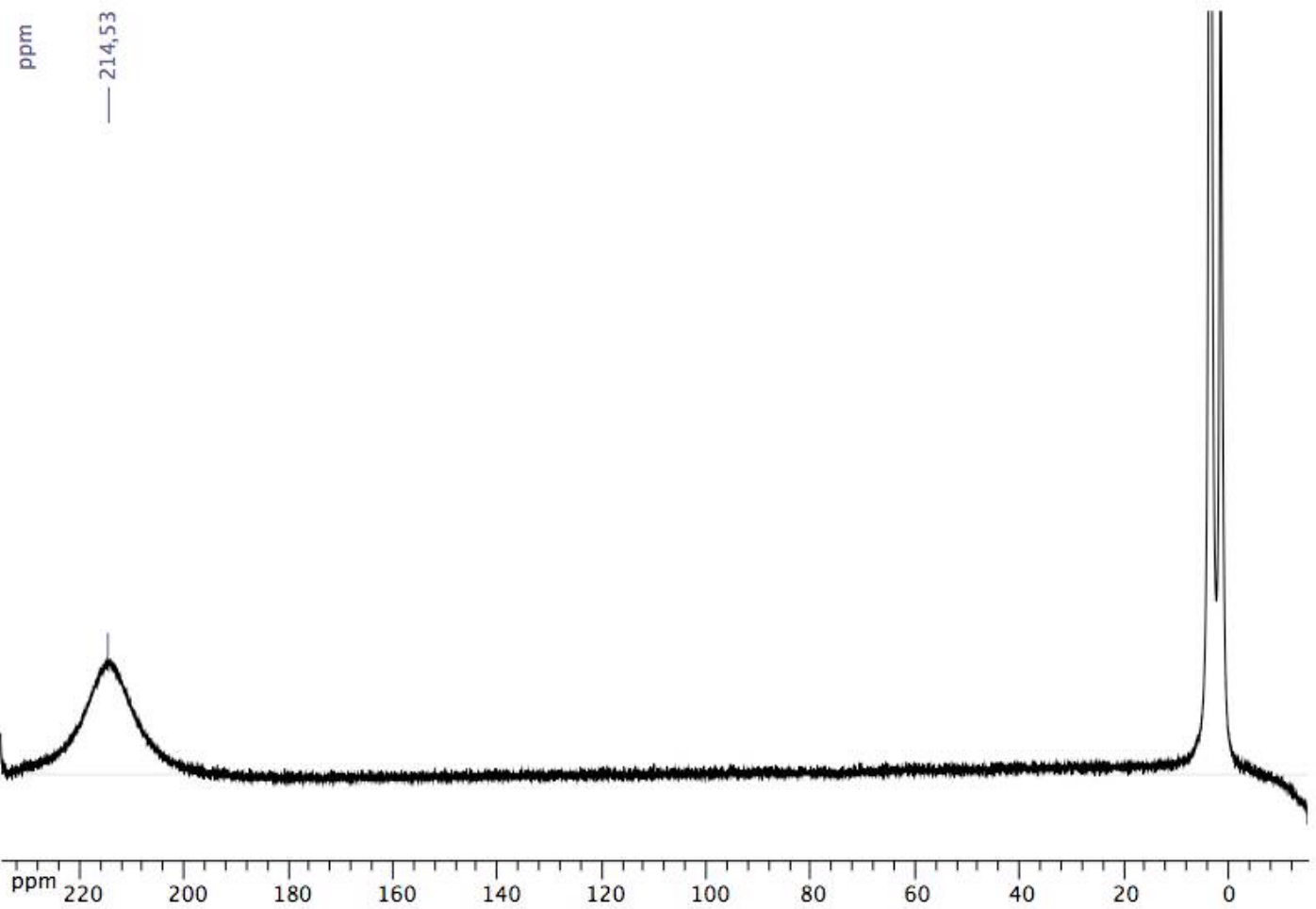

NMR spectrum of 7 in cyclohexane-d ${ }^{12}$. 


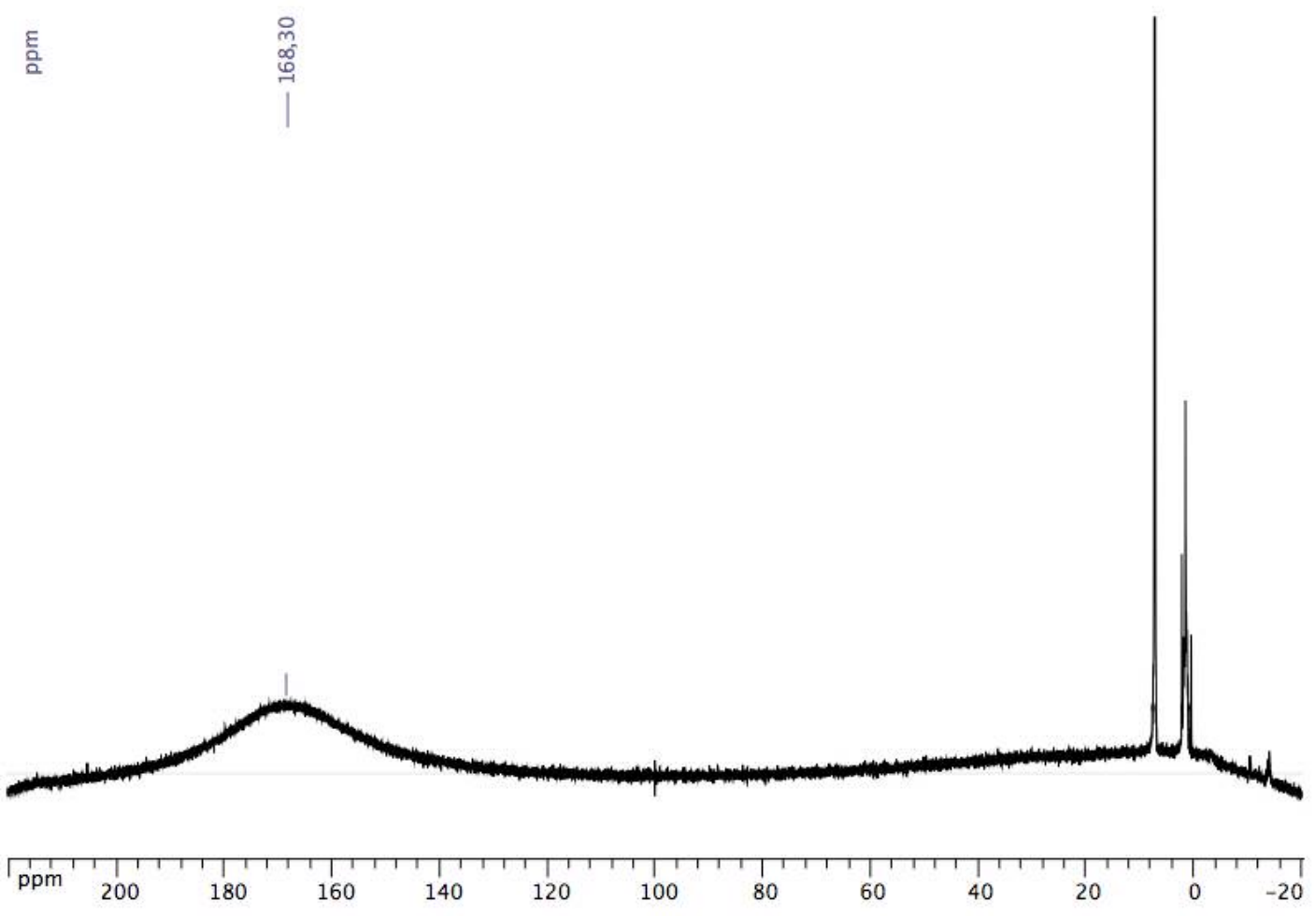

NMR spectrum of $\mathbf{8}$ in benzene-d ${ }^{6}$.
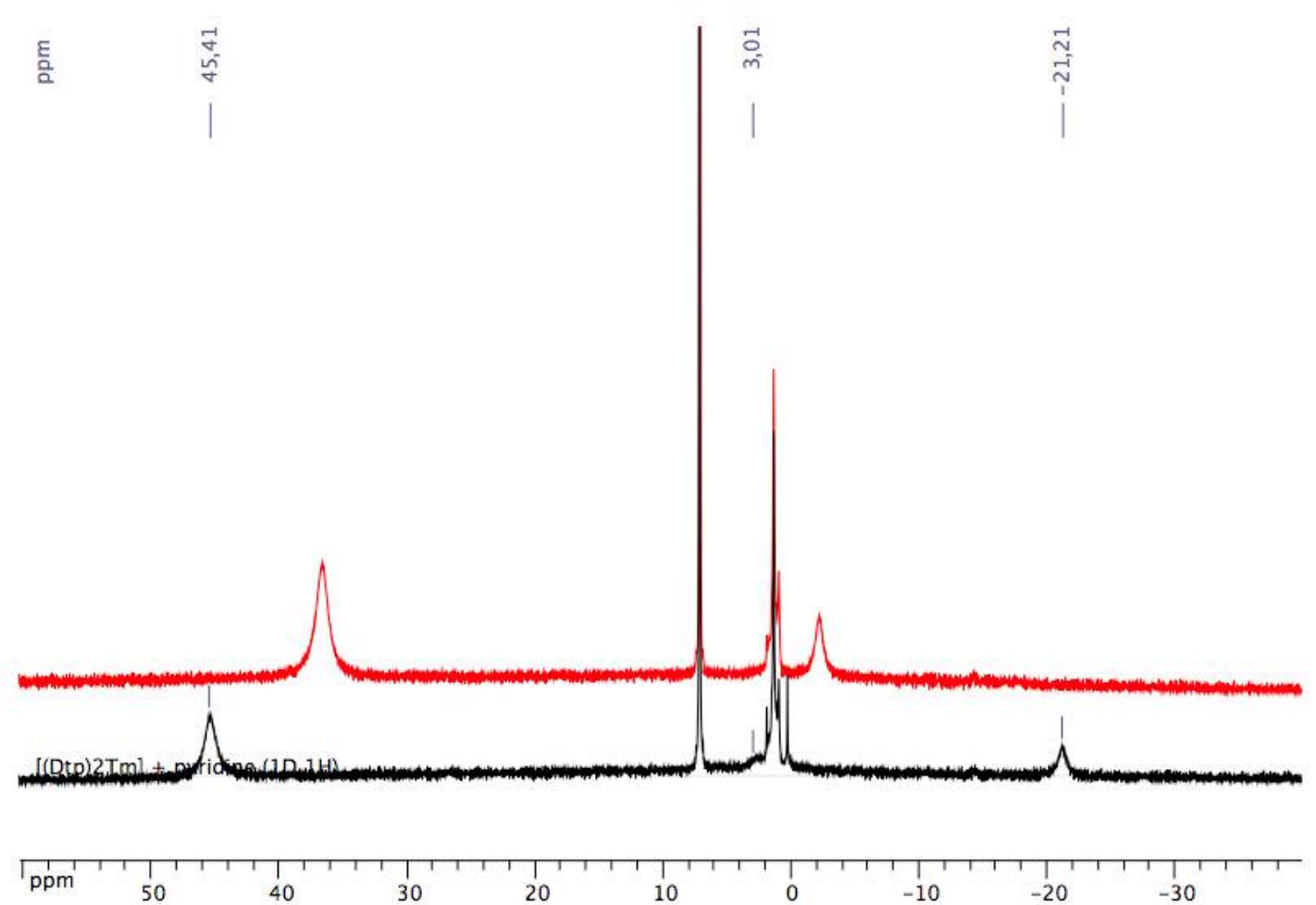

Top trace (red): NMR spectrum of [(Dtp) $\left.)_{2} \mathrm{Tm}\right]$

Bottom trace (black): NMR spectrum of $\left[(\mathrm{Dtp})_{2} \mathrm{Tm}\right]+$ pyridine $(1: 1$ mixture $)$ 